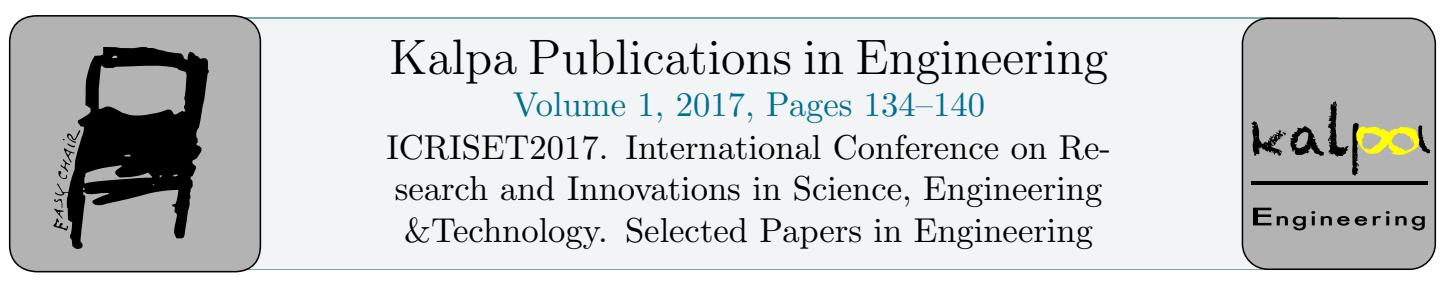

\title{
Ferro Fluid Based Rough Porous Tilted Pad Bearing with Slip Effect
}

\author{
Snehal Shukla ${ }^{1 *}$ and Gunamani Deheri ${ }^{2}$ \\ ${ }^{1}$ Department of Mathematics, Shri R.K.Parikh Arts and Science College, \\ Petlad- 388450 (Gujarat) India \\ ${ }^{2}$ Department of Mathematics, Sardar Patel University, \\ Vallabh-Vidyanagar-388120 (Gujarat) India \\ snehaldshukla@gmail.com
}

\begin{abstract}
The focus of this paper is to propose an innovative mathematical model, which describes the influence of slip and transverse roughness on a hydromagnetic squeeze film in porous tilted pad bearing. The stochastic model of Christensen and Tonder is, applied to evaluate the effect of surface roughness. Beavers and Joseph slip model takes the care of slip effect. Applying these models which governing the fluid pressure; is solved for the calculation of load support. The closed form solution is, obtained for the pressure and load capacity as a function of various physical parameters. The effect of such parameters is, discussed through graphical representations. The computations indicate that slip has to be at minimum for any upgrading in the bearing design. Besides, the absence of flow fails to keep away the bearing from supporting good amount of load, which does not happen in the case of traditional lubricant.
\end{abstract}

Key words: Tilted pad, Porosity, Ferro fluid, Roughness, Slip velocity, Load support.

\section{Introduction}

In 1905, Michell was first introduced Tilted-pad bearings. In 1910, Kingsbury discussed this bearing with a little altered context. Rouleau and Steiner [1] studied the slip effect with a same other boundary condition and gave a comparison with findings of Darcy's law based method. Miyan [2] developed a mathematical model to analyze the load capacity of fitted bearings under the effect of low and high rotation number. The load capacity was found to increase with increasing rotation number.

To develop efficient techniques for using and storing rocket engine propellants under zero gravity region NASA prepared kerosene based magnetic fluid in 1960. A magnetic field kept this fluid at the required location. In fact, this magnetic fluid consisted of a stable colloidal suspension of magnetic nano particles. Rosensweig [3] investigated the properties of ferrofluids in early 1970s. His investigations underlined the importance of 
the use of magnetic fluid in seals and bearings. Ferrofluid based bearing system was particularly interesting for low load applications that required fast and high precision positioning. Therefore, microscopy, wafer/chip inspection and pick and place machines made use of magnetic fluid based structure. Urreta et al. [4] summarized the investigations on journal bearing performance lubricated with ferro fluid. Recently, Farhad et al. [5] embarked on an analysis for investigating the effects of magnetohydrodynamic flow of blood, which was represented as a casson fluid under the consideration of fractional model.

Surface roughness characterization on the lubricated surface has been discussed in depth during the last two and half decades. Now a day, it is well recognized that load support and friction are saviourly affected by the composite roughness of the surfaces. Both, Stochastic and Gaussian roughness models were studied by Adamu and Sinha [6] under the influence of thermal effect on infinitely long tilted pad bearing.

Here, it has been proposed to discuss the load bearing support on behaviour of a transversely rough tilted pad porous bearing with slip in the presence of a magnetic fluid. A model is developed using this method that is then validated with another setup model by Shukla and Deheri [7]. The resulting compression can be used to understand how a ferrofluid bearing should be designed to meet the desired load under the influence of slip and porosity.

\section{Mathematical Modeling}

The bearing structure is presented in Fig. 1, in which the runner feeds oil into a converging wedge. The gap $h$ increases with increasing $x$, that is why runner has to move towards the origin with velocity $-U$ The position of $h_{0}$ is a distance $H_{1}$ from the origin while $h_{1}$ is away by a distance $H_{1}+B$.

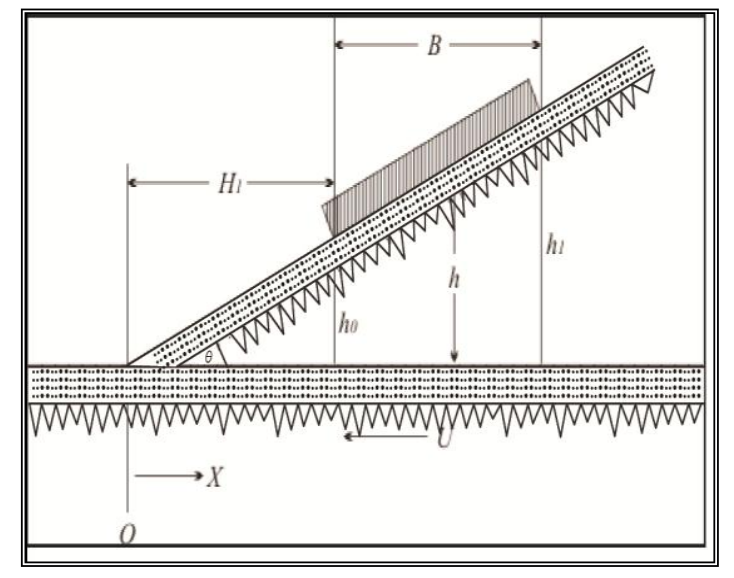

Figure 1: The Schematic Sketch of the Pattern

By Similarity of triangles gives

$$
h=\frac{x h_{0}}{H_{1}}, \quad H_{1}=B\left(\frac{h_{0}}{h_{1}-h_{0}}\right)=\frac{B}{K}, K=\frac{h_{1}-h_{0}}{h_{0}}
$$

In view of Christensen and Tonder [8] the film thickness is describes as

$$
h(x)=\bar{h}(x)+h_{s}
$$

The magnitude of the magnetic field is given by considering $k=10^{14} A^{2} \mathrm{~m}^{-4}$ with the magnetic strength over $10^{5}$ (Bhat [9]). 


$$
H^{2}=k B\left(\frac{h}{h_{0}}-1\right)\left(K+1-\frac{h}{h_{0}}\right)
$$

It is well know that (Cameron [10]), the Reynolds type equation associated with inclined slider bearing is given by

$$
\frac{d P}{d x}=-6 U \eta \frac{h-\bar{h}}{h^{3}}
$$

Inclusion of porosity (Prajapati [11]) in equation (3) turns in

$$
\frac{d P}{d x}=-6 U \eta \frac{h-\bar{h}}{h^{3}+12 \varphi H}
$$

By applying Neuringer and Rosensweig [12] model based ferrofluid lubrication transfer to equation (4)

$$
\frac{\mathrm{d}}{\mathrm{dx}}\left(P-\frac{\mu_{0} \bar{\mu} H^{2}}{2}\right)=-6 U \eta \frac{h-\bar{h}}{h^{3}+12 \varphi H}
$$

Now, with the aid of stochastic average model of Christensen and Tonder [8], one is inclined to obtain

$$
\frac{\mathrm{d}}{\mathrm{dx}}\left(P-\frac{\mu_{0} \bar{\mu} H^{2}}{2}\right)=-6 U \eta \frac{\sqrt[3]{a(h)} h-\bar{h}}{a(h)}
$$

where

$$
\mathrm{a}(h)=h^{3}+3 \alpha h^{2}+3\left(\sigma^{2}+\alpha^{2}\right) h+\varepsilon+3 \sigma^{2} \alpha+\alpha^{3}+12 \varphi H
$$

Lastly, in view of Beavers and Joseph [13] slip model one arrives at

$$
\frac{\mathrm{d}}{\mathrm{dx}}\left(P-\frac{\mu_{0} \bar{\mu} H^{2}}{2}\right)=-6 U \eta \frac{1}{S} \frac{\sqrt[3]{a(h)} h-\bar{h}}{a(h)}
$$

Where

$$
S=\frac{4+s h}{2+s h}
$$

The concerned boundary conditions are

$$
P=0, \quad h=h_{1} \text { and } h=h_{0}
$$

The following non-dimensional quantities are introduced to develop mathematical model.

$$
\begin{gathered}
P^{*}=\frac{h_{0}{ }^{2}}{6 U \eta B} P, \mu^{*}=\frac{k \bar{\mu} \mu_{0} B h_{0}{ }^{2}}{U \eta}, \varepsilon^{*}=\frac{\varepsilon}{h_{0}{ }^{3}}, \sigma^{*}=\frac{\sigma}{h_{0}}, A(h)=\frac{a(h)}{h^{3}} \\
\alpha^{*}=\frac{\alpha}{h_{0}}, \quad \varphi^{*}=\frac{12 \varphi H}{h_{0}{ }^{3}}, W^{*}=\frac{W h_{0}{ }^{2}}{6 U \eta L B^{2}}, S^{*}=S h_{0}, h^{*}=\frac{h}{h_{0}}
\end{gathered}
$$

The non-dimensional pressure variation in the bearing system is found to be

$$
P^{*}=h^{*}\left(h^{*}+1\right) \frac{\mu^{*}}{2}+\frac{1}{K A(h)}\left[\frac{1}{h^{*}}-\frac{K+1}{(K+2) h^{* 2}}-\frac{1}{K+2}\right] \frac{1}{S^{*}}
$$

The load carried per unit length $W / L$ is the integral of the pressure over the pad, leads to

$$
W^{*}=\frac{\mu^{*}}{18}\left(3 K-2 K^{3}\right)+\frac{1}{K^{2} A(h)}\left[\log (k+1)-\frac{2 K}{(K+2)}\right] \frac{1}{S^{*}}
$$




\section{Graphical Results and Discussion}

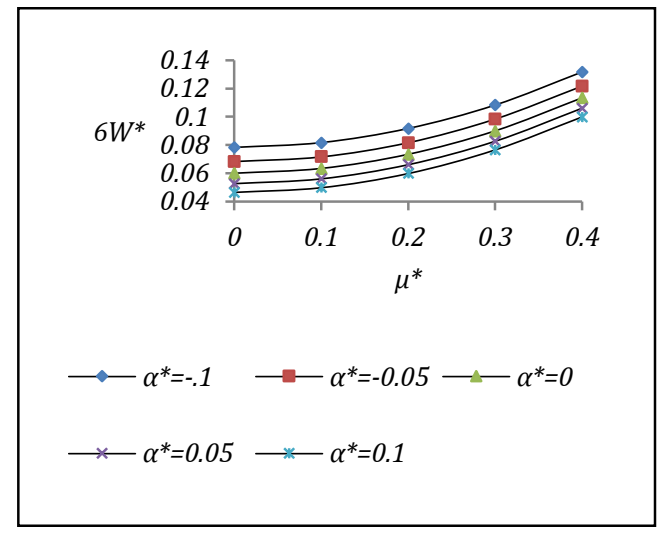

Figure 2: Load support variation with $\boldsymbol{\mu}^{*}$ and $\boldsymbol{\alpha}^{*}$

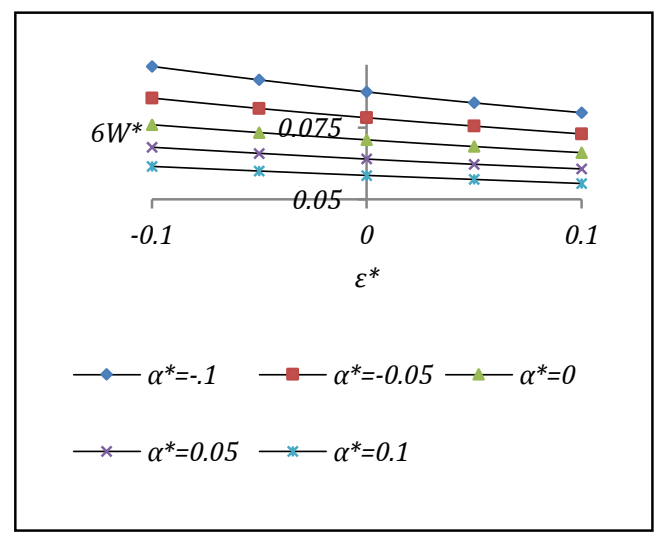

Figure 4: Load support variation with $\boldsymbol{\varepsilon}^{*}$ and $\boldsymbol{\alpha}^{*}$

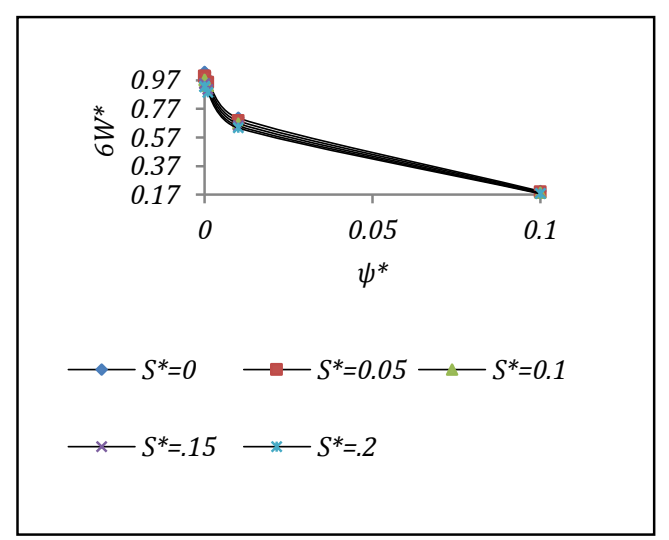

Figure 6: Load support variation with $\varphi^{*}$ and $S^{*}$

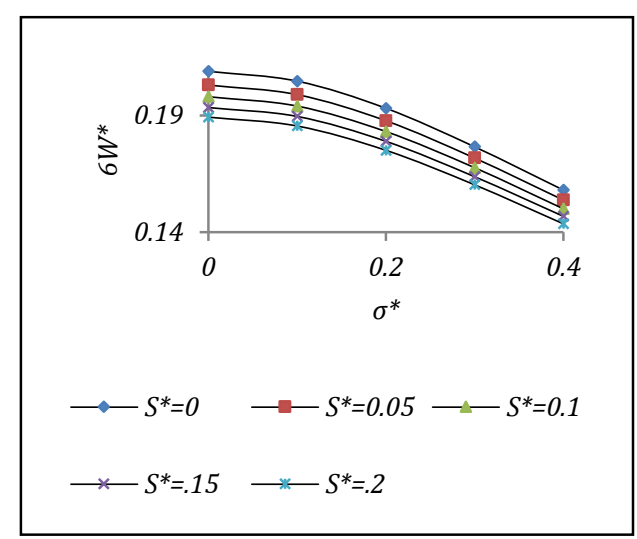

Figure 3: Load support variation with $\boldsymbol{\sigma}^{*}$ and $\boldsymbol{S}^{*}$

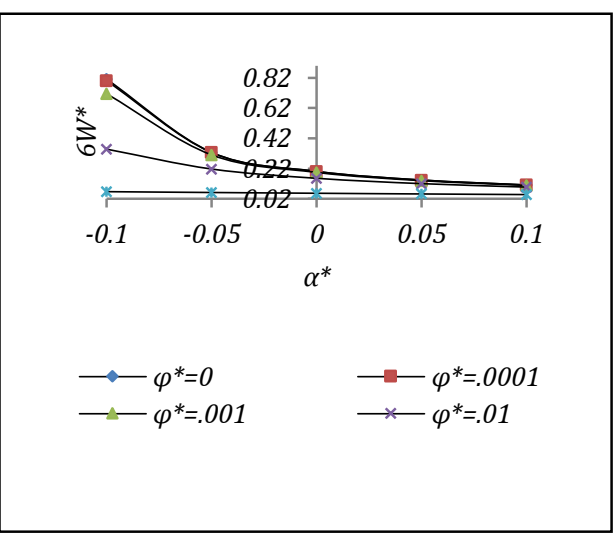

Figure 5: Load support variation with $\alpha^{*}$ and $\varphi^{*}$

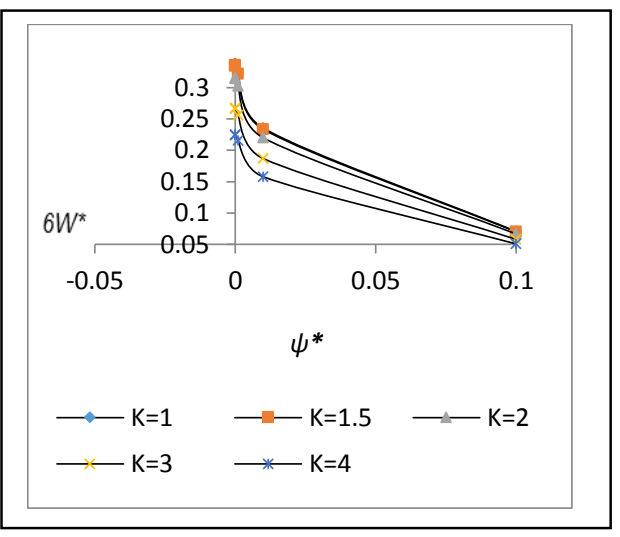

Figure 7: Load support variation with $\varphi^{*}$ and $K$ 
It is manifested that the expression for the load support is linear with respect to $\mu^{*}$, and hence the dimensionless load increases with increasing $\mu^{*}$ as shown in Fig.2. The magnetization results in an improved performance because it increases the viscosity of the lubricant leading to an increase in pressure; thus giving increased load support.

The standard deviation has a substantial adverse effect on the performance of the hydrodynamic squeeze film which can be seen from Fig. 3. Roughness retards the motion of the lubricant and hence causes abridged pressure resulting in decrease the load. In the Fig.3, considerably decreasing behavior of slip is noticed. One can examine the variation of load capacity with respect to skewness from Fig. 4. It reveals that $\varepsilon^{*}(+v e)$ decreases the load, while $\varepsilon^{*}$ (-ve) increasing in load capacity. The next important parameter, which should be taken into account, is the behaviour of load support trends with variance configuration in Fig. 5. It is found that the variance follows the trends of the skewness. It is appealing to note that the effect of the porosity on distribution of the load support with respect to variance is negligible up to 0.001 . Furthermore, it can be visualized that the combined effect of $\varepsilon^{*}(-\mathrm{ve})$ and $\alpha^{*}(-\mathrm{ve})$ is significantly positive in most of the situations. One of the main goal of this investigation is to constrain effect of porosity on the distribution of load capacity. To examine this effect Fig. 6 and Fig.7 are plotted. From these graphical representations, it is clear that porosity affects the bearing system adversely. However, the system remains enhanced under the effect of $\varepsilon^{*}(-v e)$ when smaller values of $\mathrm{S}^{*}$ are considered.

\section{Validation}

In order to order to validate the accuracy of our findings our mathematical modeling scheme has been applied to the problem considered by Shukla and Deheri [7] (Paper*) with relation to the titled pad slider bearing amid porous surfaces under slip effect. The Results are compared and as can be seen, there is a good degree of accuracy and the results fell with the findings of Shukla and Deheri [7].

\begin{tabular}{|c|c|c|c|c|c|c|c|c|c|}
\hline \multirow[b]{2}{*}{ Quantity } & \multicolumn{3}{|c|}{$\begin{array}{l}\text { Load support in } \\
\text { investigation }\end{array}$} & \multirow{2}{*}{\begin{tabular}{l}
\multicolumn{1}{c}{ Paper* } \\
Without \\
Consideration
\end{tabular}} & \multicolumn{4}{|c|}{ Load support in this investigation } & \multirow{2}{*}{\begin{tabular}{l}
\multicolumn{1}{c}{ Paper* } \\
$\begin{array}{l}\text { Without } \\
\text { Consideration }\end{array}$
\end{tabular}} \\
\hline & & $\begin{array}{l}\text { With } \\
\text { Consideration }\end{array}$ & $\begin{array}{l}\text { Without } \\
\text { Consideration }\end{array}$ & & Quantity & & $\begin{array}{l}\text { With } \\
\text { consideration }\end{array}$ & $\begin{array}{l}\text { Without } \\
\text { Conside } \\
\text { ration }\end{array}$ & \\
\hline \multirow{5}{*}{$\begin{array}{r}\varepsilon^{*}= \\
0.05\end{array}$} & $\mu^{*}$ & 0.0082643 & 0.0049309 & 0.0152921 & \multirow{5}{*}{$\begin{array}{l}\sigma^{*}= \\
0.2\end{array}$} & $\mu^{*}$ & 0.043776 & 0.0404436 & 0.21433925 \\
\hline & $\alpha^{*}$ & 0.0012799 & 0.0048317 & 0.0213954 & & $\alpha^{*}$ & 0.180211 & 0.1835447 & 0.21906620 \\
\hline & $\sigma^{*}$ & 0.0049309 & 0.0123274 & 0.0135771 & & $\varepsilon^{*}$ & 0.308933 & 0.0205242 & 0.49603245 \\
\hline & $\varphi^{*}$ & 0.0049309 & 0.0064881 & -- & & $\varphi^{*}$ & 0.018658 & 0.0205242 & ------------- \\
\hline & $S^{*}$ & 0.0349309 & 0.0352210 & --- & & $S^{*}$ & 0.040363 & 0.0449373 & 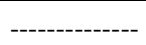 \\
\hline \multirow{5}{*}{$\begin{array}{c}\varphi^{*}= \\
0.001\end{array}$} & $\mu^{*}$ & 0.0070543 & 0.0037210 & 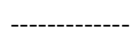 & \multirow{5}{*}{$\begin{array}{l}\alpha^{*}= \\
-0.05\end{array}$} & $\mu^{*}$ & 0.005061 & 0.0017286 & 0.09623147 \\
\hline & $\alpha^{*}$ & 0.000157 & 0.0208274 & --- & & $\varepsilon^{*}$ & 0.016226 & 0.0219147 & 0.08268433 \\
\hline & $\sigma^{*}$ & 0.000143 & 0.0037210 & ---- & & $\varphi^{*}$ & 0.004317 & 0.0049783 & ------ \\
\hline & $\varepsilon^{*}$ & 0.002495 & 0.0037210 & ---- & & $\sigma^{*}$ & 0.069196 & 0.0864765 & 0.07896604 \\
\hline & $S^{*}$ & 0.785856 & 0.8320836 & -------------- & & $S^{*}$ & 0.045936 & 0.0623987 & ---------------- \\
\hline
\end{tabular}




\section{Conclusion}

One of the conclusions of this paper is that even if there is a suitable magnetic field, the roughness must be treated carefully. The current investigation may remain suitable for designing optimal rotor dynamics.

From this investigation, remarkable out-comes have been marked:

- The magnetization has a limited option in lowering the negative effect of roughness and slip.

- The adverse influence of standard deviation and slip becomes more even for lower to moderate values of porosity.

- For any type of improvement in the performance characteristics, one is inclined to use lower values of slip.

- Although, there are many parameters reducing the bearing load, the ferrofluid lubrication turns in a better situation when the effect of trio porosity, slip and standard deviation; is at considerably low level.

\section{Acknowledgment}

The authors acknowledge with thanks the constructive suggestions and fruitful comments of the reviewers/ Editor, which has improved the presentation of the paper.

\section{References}

[1] W. T. Roulean, and L. I. Steiner, "Hydrodynamic porous journal bearing : part-I- finite full bearing," J. of Lub. Tech., Vol. 96 (3), pp. 346-353, 1974.

[2] M. Miyan, "Load capacity for fitted bearing of hydrodynamic lubrication under low and high rotation," Int. J. of Pure and App. Res., Vol. 1 (2), pp. 109- 118, 2016.

[3] R. E. Rosensweig,, "Bearing arrangement with magnetic fluid defining pads," US Patent 3734578 A, 1971.

[4] H. Urreta, Z. leicht, A. Sanchez, A. Agirre, P. Kuzhir, and G. Magnac, "Hydrodynamic bearing lubricated with magnetic fluids,” J. Intell. Mater. Sys. Struct., Vol. 21(15), pp. 1491-1499, 2010.

[5] A. Farhad, N. Sheikh, I. Khan, and M. Saqib, "Magnetic field effect on blood flow of Casson fluid in axisymmetric cylindrical tube: A fractional model," J. of Mag. And Mag. Mat., Vol. 423, pp. 327-336, 2017.

[6] G. Adamu, and P. Sinha, "Thermal and roughness effects in a tilted pad slider bearing considering heat conduction through the pad and slider," Proc. Of the National Acadamy of Sci., India section A: Physical Sciences, Vol. 82(4), pp. 323-333, 2012.

[7] S. D. Shukla, and G. M. Deheri, "Rough titled pad slider bearing lubricated with a magnetic fluid," Asian J. of Sci. and Tech., Vol. 4 (11), pp. 034-039, 2012.

[8] H. Christensen, and K.C .Tonder, "Tribology of rough surface: Stochastic models of hydrodynamic lubrication," SINTEF, Report No. 10/69-18, 1969(a).

[9] M. Bhat, Lubrication with a magnetic fluid, Team Spirit (India) Pvt. Ltd. 2003.

[10] A. Cameron, Basic theory of lubrication. John Willy and Sons, New-York, 1972.

[11] B.L. Prajapati, "On certain theoretical studies in hydrodynamic and electr magnetohydrodynamic lubrication,” Ph. D. Thesis, S.P.University, Vallabh vidyanagar, India, 1995.

[12] J. L. Neuringer, and R. E. Rosensweig, "Magnetic fluids," Phy. Of Fluids, Vol. 7 (12), pp. 19271937, 1964.

[13] G.S. Beavers and D.D. Joseph, "Boundary conditions at a naturally permeable wall," J. of Fluid Mech., Vol. 30, pp. 197-207, 1967. 


\section{Nomenclature:}

\begin{tabular}{|l|l|l|l|l|l|}
\hline $\mathrm{h}$ & $\begin{array}{l}\text { Film thickness at } \\
\text { any point }\end{array}$ & $\mathrm{h}_{0}$ & Minimum film thickness & $\alpha$ & Variance \\
\hline $\mathrm{x}$ & $\begin{array}{l}\text { Co-ordinate in axial } \\
\text { direction }\end{array}$ & $\mathrm{h}_{1}$ & Maximum film thickness & $\varphi$ & porosity \\
\hline $\mathrm{B}$ & Length of bearing & $\mathrm{h}_{\mathrm{s}}$ & $\begin{array}{l}\text { Randomly variation } \\
\text { portion }\end{array}$ & $\eta$ & viscosity \\
\hline $\mathrm{H}$ & Magnitude of field & $\mathrm{h}^{-}$ & Mean film thickness & $\sigma^{*}$ & $\begin{array}{l}\text { Non-dimensional } \\
\text { Standard deviation }\end{array}$ \\
\hline $\mathrm{L}$ & Breath of bearing & $\mathrm{P}^{*}$ & Dimensionless pressure & $\varepsilon^{*}$ & $\begin{array}{l}\text { Non-dimensional } \\
\text { skewness }\end{array}$ \\
\hline $\mathrm{P}$ & Lubricant pressure & $\mathrm{S}^{*}$ & $\begin{array}{l}\text { Dimensionless Slip } \\
\text { parameter }\end{array}$ & $\alpha^{*}$ & $\begin{array}{l}\text { Non-dimensional } \\
\text { variance }\end{array}$ \\
\hline $\mathrm{S}$ & Slip parameter & $\mathrm{W}^{*}$ & $\begin{array}{l}\text { Dimensionless Load } \\
\text { support }\end{array}$ & $\varphi^{*}$ & $\begin{array}{l}\text { Non-dimensional } \\
\text { porosity }\end{array}$ \\
\hline $\mathrm{U}$ & Runner-Velocity & $\sigma$ & $\begin{array}{l}\text { Standard deviation } \\
\mu^{*}\end{array}$ & $\begin{array}{l}\text { Non-dimensional } \\
\text { Magnetization parameter }\end{array}$ \\
\hline $\mathrm{W}$ & Load support & $\varepsilon$ & skewness & $\mu^{-}$ & Magnetic susceptibility \\
\hline
\end{tabular}

